\title{
Hereditary congenital anophthalmia: 3 cases of children of the same family
} \author{
and Koffi KV ${ }^{1}$ \\ ${ }^{1}$ Department of Ophthalmology, Bouaké University Hospital, Côte d'Ivoire \\ ${ }^{2}$ Department of Ophthalmology, Yopougon University Hospital, Côte d'Ivoire \\ ${ }^{3}$ Department of Radiology, Yopougon University Hospital, Côte d'Ivoire \\ ${ }^{4}$ Department of Ophthalmology, Cocody University Hospital, Côte d'Ivoire
}

Diomandé IA ${ }^{*}$, Sowagnon TYC ${ }^{2}$, Toure A ${ }^{3}$, Soumahoro $\mathrm{M}^{4}$, Kouassi $\mathrm{FX}^{4}$, Bilé $\mathrm{PFE}^{1}$, Diomande GF ${ }^{1}$, Koman $\mathrm{CE}^{4}$, Konan MP1 , Safédé K²

\begin{abstract}
Introduction: Congenital anophthalmia is the clinical absence of the eye at birth. It results from the lack of development or regression of the primary optic vesicle during embryonic life. It is rare and may be isolated or associated with other ocular or general birth defects.

Observations: We report the cases of three children from the same family aged between 4 months to 8 years with bilateral congenital anophthalmia. Their history is marked by a lack of consultation and prenatal laboratory tests. Ophthalmologic examination objectified, opening the eyelids with two eyes, a filling of the cavity by the conjunctival tissue in 3 cases suggestive of bilateral anophthalmia, confirmed the ocular ultrasound.

Discussion: Congenital anophthalmia is a rare malformation. It can be isolated or integrated to a malformation syndrome. The clinical picture is mostly unilateral. Diagnosis is mainly clinical and confirmed by ocular ultrasound. The causes are varied, represented by chromosomal aberrations, genetic mutations, poisoning and infections acquired during pregnancy.

Conclusion: The discovery of a congenital anophthalmia imposes a comprehensive review in order to seek the etiology. Psychological support of parents also remains an important focus.
\end{abstract}

\section{Introduction}

Anophthalmia is the clinical missing of the eye. It is an extremely rare eye abnormality. There are numerous etiologies, such as chromosomal aberrations, genetic mutations, intoxications and infections. Congenital anophthalmia can be isolated or associated with severe polymorformatives syndromes. It is responsible for, on the one hand, a micro-orbit and a homolateral craniofacial hemi-atrophy and, on the other hand, a poor development of the appendages posing problems during the prosthetic adaptation. The diagnosis has been improved by prenatal imaging and therapeutic management essentially involves orbital prostheses. We report 3 cases of bilateral congenital anophthalmia in the same family.

\section{Case 1}

It is a male child aged 8 year, born at term, received in consultation for a bilateral decrease in visual acuity. The biological and orbit-cerebral CT-scan prenatal assessment was not possible. Clinical ophthalmologic examination revealed an absence of luminous perception in both eyes; Bilateral anophthalmia; the appendages are present and normal and at the opening of the eyelids, a conjunctival structure filling the entire orbital cavity with no eyeball. The requested orbit-cerebral CT-scan has confirmed the absence of the ocular globe with the presence of residual fat, oculomotor muscles and an atrophy of the caliber of the optic nerve in the orbital cavity (Figure 1). The overall balance sheet was normal. And magnetic resonance imagery could not be realized considering the financial difficulties of the parents, as well as the genetic balance (karyotyping). Surgical treatment with placement of a prosthesis was proposed but not materialized due to a lack of adequate technical platform. (Figure 2)

\section{Case 2}

It was a male child of 8 years, in whom no prenatal assessment (biological and ultrasound echographic) was carried out. He was received in ophthalmologic consultation for a bilateral decrease in visual acuity. Clinical ophthalmologic examination found an absence of luminous perception in both eyes; A bilateral anophthalmia, appendages without particularities and at the opening of the eyelids, a conjunctival structure filling the cavity).The requested orbit-cerebral CT- scan has confirmed the absence of the ocular globe with the presence of residual fat, oculomotor muscles and an atrophy of the caliber of the optic nerve in the orbital cavity (Figure 3). The general examination of this child was normal. And magnetic resonance imaging as well as the karyotype could not be performed for the same reasons mentioned previously, as well as the medical management. (Figure 4)

Correspondence to: Ibrahim Abib Diomande, Ophthalmology Department, University Hospital of Bouaké, University Alassane Ouattara, 01 Bp 1174 Bouake 01, Côte d'Ivoire, E-mail : abib.diomande@doctor.com

Key words: anophthalmia, congenital, ocular ultrasound, chromosomal aberrations

Received: November 07, 2017; Accepted: November 24, 2017; Published: November 27, 2017 


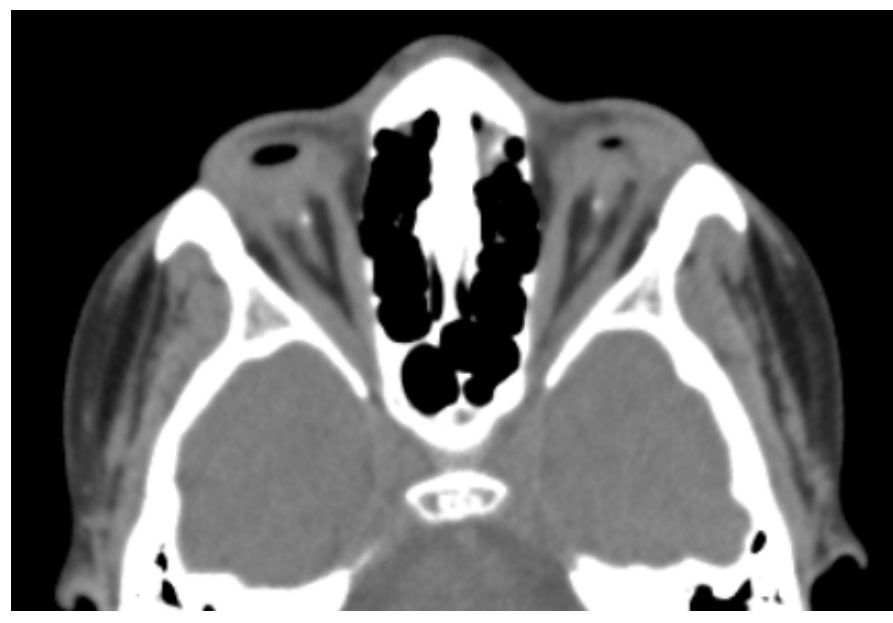

Figure 1. Orbit cerebral CT-scan: absence of the ocular globe with residual fat, muscles and an atrophy of the caliber of the otocerval nerve in the orbital cavity.

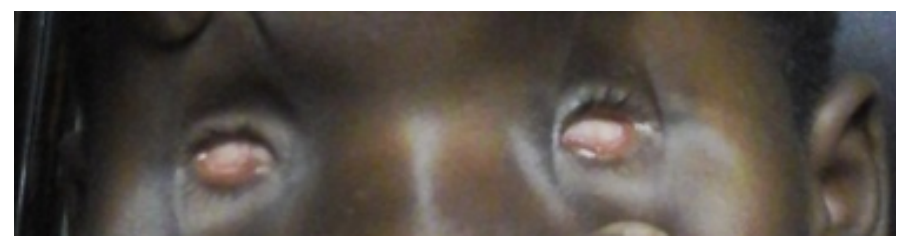

Figure 2. 8 years old child showing bilateral anophthalmos at the opening of the eyelids

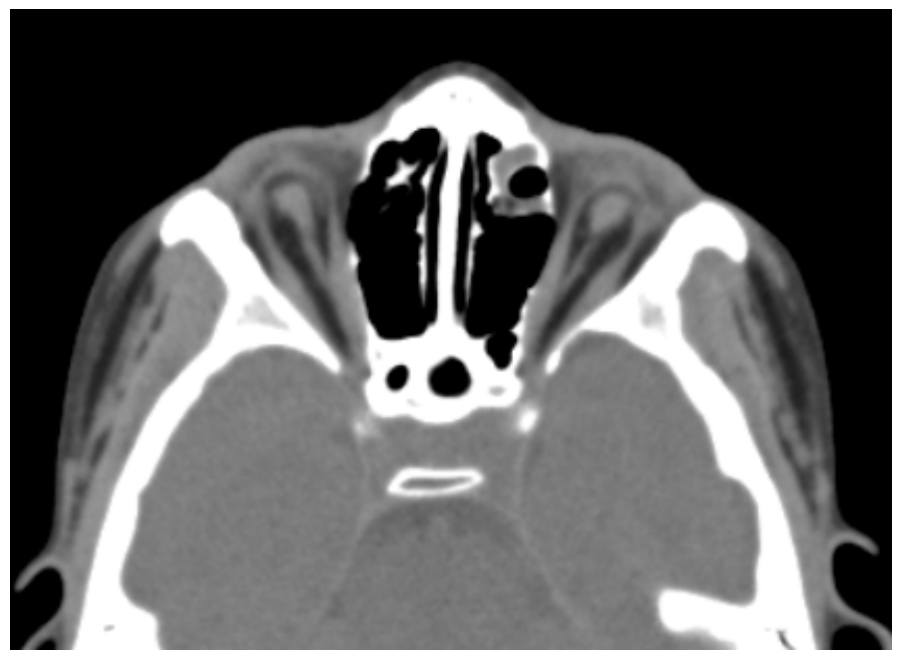

Figure 3. Absence of the ocular globe with residual fat, muscles and an atrophy of the caliber of the otocerval nerve in the orbital cavity.

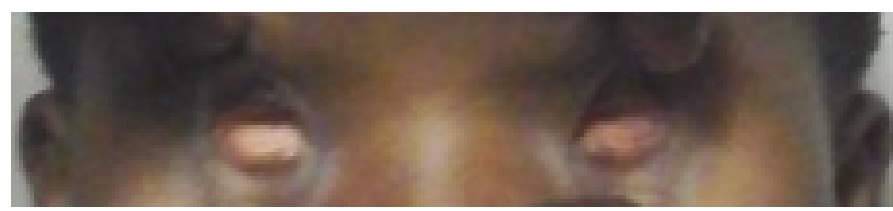

Figure 4. 6-years old child with bilateral anophthalmia at the opening of the eyelids.

\section{Case 3}

It is that of a 4 months old female infant, born at term and having good psychomotor development and staturo-weight, received in ophthalmological consultation for a bilateral decrease in visual acuity and permanent occlusion of the eyelids since birth. The infant's history is marked by two prenatal consultations, but no pre-natal biological and ultrasound scans. Clinical ophthalmologic examination found an absence of luminous tracking; Bilateral anophthalmia; normal aspects of the appendages and to the opening of the eyelids, an ocular globe blank giving a microphthalmic appearance, the details of the iris are not analyzable and an absence of an anterior chamber. The pediatric consultation in search of other malformations returned with no particularity on the clinical level.

The requested orbit-cerebral tomography has confirmed the absence of an ocular globe with the presence of residual fat, oculomotor muscles and an atrophy of the caliber of the optic nerve in the orbital cavity (Figure 5). Magnetic resonance imaging and the karyotyping could not be performed; as well as his medical management (Figure 6).

\section{Discussion}

Congenital anophthalmia or clinical absence of the eye at birth [1] is a rare malformation [2]. Its incidence is variable. It is estimated at less than one case per 10000 births for Mouriaux and Roth [3,4]. It would be about 21.34 per 100,000 births according to a Spanish survey [5] and 10 per 100,000 births according to a British study [6]. For Aranjo [7], its incidence is 0.6 per 10000 children born alive. This difference in incidence finds its explanation in the variability of occurrence of this malformation. The frequency of anophthalmia is not influenced by race or sex. Anophthalmia can be isolated or integrated into a polymalformative syndrome in one third of cases [1]. This observation is in conformity with those of several authors. Thus, for Verna [8], both anophthalmia and microphthalmia may occur in isolation or be integrated into a syndrome of Patau (trisomy13) or other syndromes in about one third of the cases. Kouassi [9] also reported a case of bilateral congenital anophthalmia during the syndrome of Patau. So does Diomandé [10] in Bouaké who reported a case of a real congenital anophthalmia associated with severe microphthalmia in a newborn without any other observed clinical abnormalities.

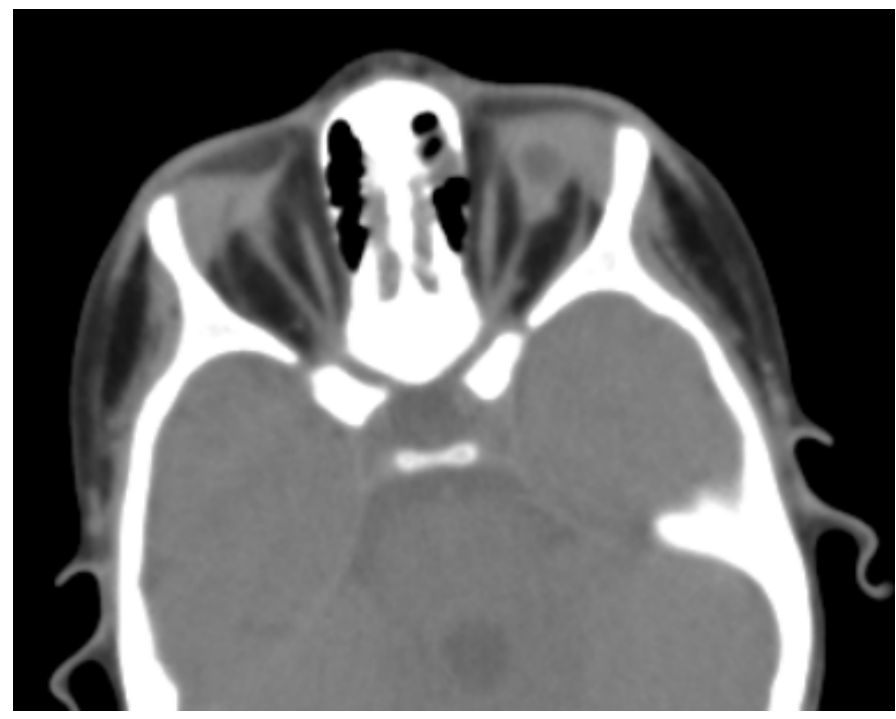

Figure 5. A absence of an ocular globe with a residual vesicle, muscles and an atrophy of the otocerval nerve in the orbital cavity.

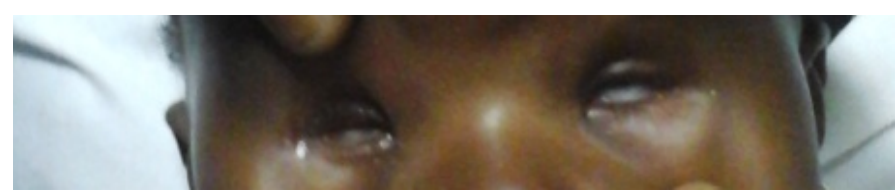

Figure 6. 4 months old child; at the opening of the eyelids we could notice, especially in the right eye a sketch of corneal but the iris is not individualizable. 
In addition, Stoll [11] noted that $90 \%$ of anophthalmia had associated malformations. Therefore, in the presence of any congenital anophthalmia or extreme microphthalmia, it is important to perform a thorough pediatric assessment in search of associated abnormalities, sometimes severe such as anencephaly or agenesis of the entire optic tract [1]. Clinical anophthalmia is rarely bilateral. Modern paraclinical investigations such as computed tomography and magnetic resonance imaging make it possible to investigate the associated malformations. In our observations, these balances could not be realized given the socio-economic difficulties of the parents.

According to Speeg - Schatz [1], there are three types of congenital anophthalmia: primary anophthalmitia, secondary anophthalmos and consecutive secondary anophthalmia as a result of absence of invagination of the optic fossa, the complete cessation of the development of the anterior neural tube or the degeneration of the optic vesicle after its invagination. For Stricker [12], congenital anophthalmitia could be analyzed and classified according to two modes.

From the anatomical point of view, it would be necessary to distinguish true anophthalmia from embryopathies characterized by the absence of any ocular outline. Only histological examination would confirm this.

From the clinical point of view, clinical anophthalmia or extreme microphthalmia must be separated from other more moderate microphthalmia with sometimes better functional prognoses. In the later cases, there is a more or rudimentary eyeball (as in our $3^{\text {rd }}$ clinical cases) sometimes accompanied of a colobomatous cyst capable of acting as a physiological expansive prosthesis. Clinically, there is no ocular structure, but an ocular ultrasound, computed tomography and magnetic resonance imaging would show the presence of a sketch of the eyeball and the optic nerve.

However, Morax [13], noted that true anophthalmia did not exist. According to him in the most marked clinical cases, neuroimaging would show the presence of an optic nerve and a tiny ocular sketch. In our first two clinical cases, ocular ultrasound showed an absence of ocular roughing. However, in the absence of CT-scan and MRI results, we cannot formally conclude that there is no ocular optic nerve and no optic nerve.The etiology of anophthalmia is complex and diverse. It may be hereditary by chromosomal aberrations, in particular trisomy 13 or trisomy 18 . In this case, it is anophthalmia with cerebral malformations or associated with a dysplasia of the median line [1]. Other genetic etiologies are represented by chromosomal mutations that may occur during chromosomal deletions or independently of any aberration of the karyotype. SOX2 anomalies are the main ones. Fantes [14] diagnosed a microdeletion associated with a translocation $\mathrm{t}(3 ; 11)$ (q26-3 p11-2) and mutation of the SOX2 gene in a patient with bilateral anophthalmia. The haploinsufficiency of SOX2 is believed to be responsible for anophthalmia, microphthalmia, septooptic dysplasia and a defect in development of the anterior brain [15]. Ye [16] noted that the SOX2 defect would cause a multiple disorder of the organic system including anophthalmia and microphthalmia. Other genes, such as PAX6, OTX2, CHV10, RAX2, SIX6, NF1, TWIST, SHH, BMP4 and BMP7, would be involved in the occurrence of anophthalmia. According to Schilter [16], less than $40 \%$ of known genetic mutations would explain anophthalmia. For him, a mutation of the genes NF1, PAX6, SOX2 would be responsible for anophthalmia or microphthalmia. You [18] described a mutation of the OTX2 gene associated with anophthalmia and congenital microphthalmia in a Chinese family. Veronica [19] observed, in one patient, a mutation of the RAX2 gene responsible for unilateral anophthalmia. Mutations in the TWIST gene during chromosome 7 deletions may lead to facial dysgenesis with anophthalmia [14]. The identification of the mutation of an allele of the SIX6 gene in a patient with bilateral anophthalmia was noted by Gallardo [20].

Without karyotyping, we are not able to attribute these hereditary anophthalmos in our study to a particular type of mutation. Moreover, the syndrome of Patau which is one of the main etiologies cannot be retained clinically in our patients.

Of all these etiological factors, the theory of genetic mutation seems to fit with our clinical cases, indeed, these 3 cases come from the same family, but also from a consanguineous coupling because they themselves come from the same family because Being cousins. However, it should be noted that vitamin A deficiency, exposure to $\mathrm{x}$-ray, abusive use of solvent, thalidomin intake and infections acquired during pregnancy would also be environmental factors [2]. The diagnosis of anophthalmia can be made pre-or post-natal based on a combination of clinical signs, imaging and genetic analysis. Dufit [21], using new imaging techniques (fetal MRI) has described a case of fetal anophthalmia associated with multiple malformations leading to termination of pregnancy.

In children, prosthetic treatment by increasing size conformers, or even techniques of orbital expansion by inflatable prostheses, is recommended before the age of 2 years. However, in adults, this type of treatment becomes unnecessary and discouraged. The therapeutic regimen must include an enlargement of the osseous orbit by different osteotomies associated at the same time or secondarily with the restoration of the conjunctival sac by mucosal graft or dermo-epidermal graft. Then, restoration of the eyelids will occur by reconstruction, repositioning and correction of the malposition on the prosthesis [13]. In our developing countries, this type of heavy and sometimes disappointing treatment is difficult to achieve by sometimes untrained teams. Moreover, the level of poverty of the parents limits their accessibility to the treatment, with aesthetic consequences and a major social repercussion.

\section{Conclusion}

Anophthalmia is extremely rare. Its diagnosis involves the investigation of both associated etiologies and malformations. Its treatment is heavy and not accessible sometimes to children of unfavorable social class resulting in aesthetic prejudice. Qualifying training for antenatal diagnosis, early management by trained specialists and an adequate technical platform are the essential means to reduce the social harm.

\section{Ethics statement}

These cases report followed the tenets of the Declaration of Helsinki and was approved by the Center Hospital University of Bouaké. Consent was obtained from the parents of the newborn and there is no conflict of interest about this article.

\section{References}

1. Speeg-Schatz, Le Marec B. Erreurs génétiques et œil in: Flamment J, Storck D. Eil et pathologie générale Rapport de la soc Fr Ophtalmol. Masson ed, Paris; 1997. P27

2. Guthoff R, Klein R, Lieb WE (2004) Congenital cystic eye. Graefes Arch Clin Exp Ophthalmol 242: 268-271. [Crossref]

3. Mouriaux F, Audo I, Defoort-Dhellemmes S, Labalette P, Guilbert F, et al. (1997) [Management of congenital microphthalmos and anophthalmos]. J Fr Ophtalmol 20: 583-591. [Crossref] 
4. Roth P, Roth A, Riethmuller D. Ophtalmologie fœtale: l'utilité de l'examen des yeux au cours de l'échographie anténatale. Ophtalmologie 1997; 11: 85-96.

5. Romero Caballero MD, López Soler JA, Alcázar Cantos A (2002) [Anophthalmia as an isolated congenital defect]. Arch Soc Esp Oftalmol 77: 571-574. [Crossref]

6. Busby A, Dolk H, Collin R, Jones RB, Winter R (1998) Compiling a national register of babies born with anophthalmia/microphthalmia in England 1988-94. Arch Dis Child Fetal Neonatal Ed 79: F168-173. [Crossref]

7. Araujo J E, Kawanami TE, Nardozza LM, Milani HJ. Oliveira PS, Monron AF (2012) Prenatal diagnosis of bilateral anophthalmia by $3 \mathrm{D}$ "reverse face" view ultrasound and magnetic resonance imaging. Taiwan J Obstet Gynecol 51: 616-619. [Crossref]

8. Verma AS, Fitzpatrick DR (2007) Anophthalmia and microphthalmia. Orphanet J Rare Dis 2: 47. [Crossref]

9. Kouassi FX, Koffi KV, Safede K, Cochard C, Cochener B (2006) [Congenital anophthalmias: a case of trisomy 13]. J Fr Ophtalmol 29: e10. [Crossref]

10. Diomande I.A, Toure.A, Koffi. K.V, Diomande.G F, Djiguimde.W P, N Habib, A. Ahnoux-zabsonre (2015) Anophthalmia and serious microphthalmia: a summary of the problems associated with antenatal diagnosis and therapeutic refunding in SubSaharan. Africa International Medical Case Reports Journal 8: 287-290.

11. Stoll C, Dott B, Alembik Y, Roth MP (2012) Associated malformations among infants with anophthalmia and microphthalmia. Birth Defects Res A Clin Mol Teratol 94: 147152.12. [Crossref]

12. Stricker M, Gola R (1990) L'anophtalmie congénitale Chirurgie plastique et réparatrice des paupières et de leurs annexes.Paris : Masson, 177-191.
13. Morax.S (1998) Anophtalmies microphtalmies in: Adenis JP, Morax S. Pathologie orbito-palpébrale. Rapport de la Soc Fr Ophtalmol. Paris: Masson. 635-645.

14. Fantes J, Ragge NK, Lynch SA, McGill NI, Collin JR, et al. (2003) Mutations in SOX2 cause anophthalmia. Nat Genet 33: 461-463. [Crossref]

15. Lee B, Song H, Rizzoti K, Son Y, Yoon J, et al. (2013) Genomic code for Sox2 binding uncovers its regulatory role in Six3 activation in the forebrain. Dev Biol 381: 491-501. [Crossref]

16. Ye FX, Fan XQ (2012) [SOX2 defect and anophthalmia and microphthalmia] Zhonghua Yan Ke Za Zhi 48: 1049-1052. [Crossref]

17. Schilter KF, Reis LM, Schneider A, Bardakjian TM, Abdul-Rahman O, et al. (2013) Whole-genome copy number variation analysis in anophthalmia and microphthalmia. Clin Genet 84: 473-481. [Crossref]

18. You T, Lv Y, Liu S, Li F, Zhao Y, et al. (2012) Novel OTX2 mutation associated with congenital anophthalmia and microphthalmia in a Han Chinese family. Acta Ophthalmol 90: e501-502. [Crossref]

19. Voronina VA, Kozhemyakina EA, O'Kernick CM, Kahn ND, Wenger SL, et al. (2004) Mutations in the human RAX homeobox gene in a patient with anophthalmia and sclerocornea. Hum Mol Genet 13: 315-322. [Crossref]

20. Gallardo ME, Rodríguez De Córdoba S, Schneider AS, Dwyer MA, Ayuso C, et al. (2004) Analysis of the developmental SIX6 homeobox gene in patients with anophthalmia/microphthalmia. Am J Med Genet A 129A: 92-94. [Crossref]

21. Dufit C, Baggio E, Ruban JM, Buenerd A, Hermier M (1999) Fetal anophthalmos Problem of the prenatal diagnosis: a case report. J Fr Ophtalmol 22: 966-969. [Crossref]

Copyright: @2017 Diomandé IA . This is an open-access article distributed under the terms of the Creative Commons Attribution License, which permits unrestricted use, distribution, and reproduction in any medium, provided the original author and source are credited. 